\title{
A Study on the Support and Direction of Lifelong Education for Adults with Developmental Disabilities in Korea
}

\author{
Kyong Jun Lee ${ }^{1}$ \\ ${ }^{1}$ Professor, Department of Social Welfare, Joongbu University, South Korea, lp2094@naver.com
}

\begin{abstract}
The purpose of this study is to discuss the reality, policy base, and future direction of lifelong education for adults with developmental disabilities in Korea. The research methods for achieving this goal were: literature analysis of prior studies, such as research reports on lifelong education for people with disabilities, and content analysis of major relevant acts and official documents. The contents included the definition of the concept, necessity, and significance of lifelong education, and the necessity and purpose of lifelong education for people with disabilities. The current status and demands of the lifelong education rights of adults with developmental disabilities in Korea wear analysed, and the current state of policy support for people with disabilities, including adults with developmental disabilities given the revision of the Lifelong Education Act. We also discuss the problems with and responses to lifelong education for persons with developmental disabilities in the recent COVID-19 situation. We derived the following factors being needed to support lifelong education and improve its direction for adults with developmental disabilities in Korea: the establishment of a concept and philosophical approach to lifelong education for such adults, measures for providing independent living, expansion of the budget, training, and placement of support experts, and the creation of an integrated environment for persons with disabilities and non-disabilities. Finally, we propose a plan to guarantee the right to lifelong education for adults with developmental disabilities in a disastrous situation such as the COVID-19 pandemic.
\end{abstract}

Keywords: Adults with Developmental Disabilities, Lifelong Education for People with Developmental Disabilities, Lifelong Education Act, the Basic Plans for Lifelong Education Promotion, COVID-19

\section{Introduction}

The term "lifelong education" is no longer unfamiliar to us living in the 21 st century. Although the concept can be interpreted differently by many scholars, it is generally consistent with the interpretation that lifelong education is a new educational network which integrates and reconstructs the former kinds of educational activities of the entire society[1]. This is a process of socialization that permeates human life through the medium of education, which can be reinterpreted as a human effort to seek integration and change with both traditional and ever new elements.

The concept of lifelong education that has been developed by UNESCO implies, first, that lifelong education aims to improve the quality of human life. Second, lifelong education is a continuous process of life from birth to death. It is a vertical integration of education for infants, early childhood, youths, and adults. Third, lifelong education enables everyone to receive lifelong education by horizontally integrating education that covers all areas of human life, such as home, society, and school. Fourth, lifelong learning is characterized by learners' self-direction, and their educational abilities and motivation are important. Fifth, lifelong education strives to make the whole society an educational

Received: November 12, 2020; $1^{\text {st }}$ Review Result: January 04, 2021; $2^{\text {nd }}$ Review Result: February 19, 2021 Accepted: March 29, 2021 
environment. In other words, it is an educational ideology that pursues greater socialization of society[2].

Hence lifelong education is a right that everyone should be equally guaranteed and contains important purposes and functions for designing and maintaining an individual's life. Having such a right implies that the most essential effort is to create a better quality of life through education. It also implies that lifelong education should increase an individual's potential as much as possible and ultimately promote the ability to actively participate in individual and social development as a member of the community.

People with disabilities may have some constraints on living a seamlessly driven life because of their inevitable intellectual, physical, and emotional characteristics. As a result, there are cases in which developmental aspects and restrictions are different from those of non-disabled persons, so continuous education is required even after persons enters adulthood, because they may show different type of development patterns or have constraints that differ from those of non-disabled people.

In order to ensure smooth self-learning and social activities, Article 24 of the UN Convention on the Rights of the Person with Disabilities stipulates 'The Right to Education'. It is meaningful to emphasize that overall national policy should provide reasonable accommodation based on the correlation between education and rights of persons with disabilities. The UN Convention implies a lifelong education perspective during the life cycle from school age to adulthood when it says, State Parties shall ensure that persons with disabilities are able to access general tertiary education, vocational training, adult education and lifelong learning without discrimination and on an equal basis with others. To this end, State Parties shall ensure that reasonable accommodation is provided to persons with disabilities.

That is, disabled people should not only be the subjects of lifelong education as citizens, but also be educated in a system in which they can learn what they want anytime and anywhere. Such a natural type of lifelong education is very important for the disabled, in that they can exercise the right to learn in order to live in a highly industrial society[3].

The start of lifelong education is the paradigm shift of education[1]. Lifelong education for disabled adults provides learning opportunities that extend beyond special education for school-aged children at the compulsory education level. Furthermore, lifelong education for the disabled is based on an educational ideology and practice that enables people with disabilities to be integrated into society, be embraced by communities in it, and live a self-supporting life[4].

However, education for the disabled in Korea is still being conducted mainly for school-age children. Some people with developmental disabilities are receiving education in majors and courses with graduation from high school or are using adult programs in welfare centers for the disabled, but since the time and content of such education are often limited, support for lifelong education that can lead to independent living by disabled adults is also very scarce. Therefore, systematic and continuous lifelong education is required for people with disabilities, who have many difficulties in adapting to society as independent individuals, and administrative and institutional support is also needed.

Against the background of this recognition, Korea revised the Lifelong Education Act twice, in 2016 and 2019. The legal acceptance and improvement of lifelong education for the disabled by the revision of this law made meaningful changes to 'the 4th Basic Lifelong Education Promotion Plan (20182022)' [5], which was implemented in 2018. Also, changes are taking place in the system for promoting lifelong education, such as by the establishment of the Lifelong Career Education Team for Students with Disabilities in the Ministry of Education and the establishment of the National Lifelong Education Promotion Center. In particular, this 4th plan is the first that is consistent with the newly established regulations in accordance with Article 9, Paragraphs 2, 5, and 6, of the Lifelong Education Act, unlike the previous plan, and establishes a system for lifelong education for the disabled. It has a greater meaning, because it focuses on doing. In addition, it is a new approach to suggesting a separate customized program-support policy that considers the characteristics of disabled learners who have been ambiguously included in the vulnerable or underprivileged class[6]. The problem is that despite these 
regulations, there are considerable constraints due to the lack of awareness of the lifelong education of adults with developmental disabilities, and the lack of financial investment or infrastructure provided by local governments. Therefore, this study aims to contribute to the search for policy changes by grasping this situation.

In this context, to seek the support and direction of lifelong education for adults with disabilities, and at the same time to improve the reality of lifelong education for people with disabilities, who are likely to be discriminated against and alienated in the wake of the recent COVID-19 situation, we set up the following research issues by selecting the relevant literature to review and the relevant laws to analyze as the key research methods:

- Where do the rights and status of lifelong education for people with disabilities and with developmental disabilities in Korea remain?

- What are the contents and support status of the lifelong education policy and relevant laws for people with developmental disabilities in Korea?

- What is an alternative to summarizing the current state of lifelong education for people with developmental disabilities amid the COVID-19 situation?

\section{Research Methodology}

Literature analysis, the basis of qualitative research methods, is a data collection method based on records and statistical data that have already written, and is easy to understand the characteristics and context of the research subject. Therefore, in this study, we derived rights, actual conditions and problems by examining various previous studies related to lifelong education for people with disabilities. Furthermore, we recapitulated the main results, described their significance by deriving them. If only the interpretation of the material is performed, the subjectivity of the researchers may intervene, hence two doctoral-level researchers cross-checked the examination results and discussed them so that the objectivity could be enhanced..

This method was also used in discussions on the reality and alternatives of lifelong education for people with developmental disabilities in Korea under the COVID-19 outbreak, the last part of this study. In other words, the understanding of the situation by quoting the latest survey data and the search for alternatives in such a special situation is consequently required.

In addition, content analysis, which is also one of the qualitative research methods, is easy to give a comprehensive insight into the situation by grasping the nature of the research subject. Accordingly, in this study, we analyzed the significance by first reviewing the official literature related to lifelong education for the disabled (UNCRPD) and the main composition and contents of domestic laws and regulations. This contributes to understanding the flow and issues of the lifelong education policy for people with (developmental) disabilities in Korea, thereby serving as the basis for a suggestion that guides the future policies in the conclusion of this paper.

\section{The Right and Realities of Lifelong Learning for People with Developmental Disabilities}

Yun et al. defined the concept of lifelong education of the developmentally disabled as "career education in various institutions to respond to the needs of diverse environments of the community where the developmentally disabled enter adulthood, actively participate in various activities, and improve their attitudes and abilities for various roles"[7]. According to Baek et al., "lifelong education for disabled adults should be dealt with and recognize not only the material and economic conditions of human beings but also the quality of daily life and the value of human life; it is defined as cultivating 
attitudes, values, and morality to improve the quality of life for the disabled[8]." According to Kim[3], lifelong education refers to education that is carried out over a lifetime from birth to death and is defined as "a natural right and a fundamental right that must be guaranteed for human survival." Therefore, no human being can be excluded from the subject. This presupposes that lifelong education for people with developmental disabilities is not particularly different from lifelong education for non-disabled people, yet some differences may occur in the content required because of the nature of the disability.

In view of the preceding studies, we defined lifelong education for the disabled as the natural right that should be guaranteed for the realization of basic human rights, the importance of human life, and survival in the philosophical sense. In the personal sense, we defined it as the process of improving the quality of life of an individual, the value of an individual, the attitude, and the cultivation of morality.

Learning rights are educational rights for all people, and even if they have disabilities, people cannot be excluded from lifelong education. Even if they are developmentally disabled, with low intellectual and social adaptability, they should not be excluded from the education they can receive during their lifetime. They have the right to receive education in the desired place, where they want it, and the state and society should have an educational system suitable for the needs of the developmentally disabled. Therefore, the concept of lifelong education for the disabled pursues vertical integration of time and horizontal integration of space rather than the narrow concept of improving the quality of life of the disabled. At the same time, lifelong learning can be defined as all educational activities that are intentional, organized, and characterized by universality, synthesis, connectivity, flexibility, diversity, autonomy, and self-realization[2]. However, the reality is that lifelong education for the disabled is not so diverse or universal, unlike the ideology of lifelong education for the disabled. Therefore, lifelong education for the disabled should be fundamentally supported by the state in order to guarantee the rights of the disabled[9].

In particular, individuals with severe developmental disabilities, such as intellectual disabilities and autistic disorder, face a situation where various roles as an adult are required in an integrated community, even though official and informal educational opportunities are limited after the end of high school. However, it is difficult for the developmentally delayed to adapt themselves to society without the help of others. Therefore, education for them should be continued in order to develop personal attitudes and competencies even in adulthood after graduating from high school[7]. In addition, lifelong education is necessary to provide systematic educational opportunities to developmentally disabled persons who have not received a proper school education during school age and have become adults. Moreover, since lifelong education for persons with developmental disabilities is the most vulnerable among lifelong education for persons with disabilities, it is necessary to develop lifelong-education programs suitable for persons with developmental disabilities by grasping the current status of such lifelong education[10].

The government has announced the "2020 Plan to Promote Lifelong Education for Persons with Disabilities" as a measure for "realizing an inclusive nation." This plan is intended to form a pangovernmental joint council group to promote lifelong education for persons with disabilities, and intends to designate a lifelong-learning city for people with disabilities and newly establish a lifelong-education curriculum by means of cooperation between ministries. The key direction is to create a country where there is no discrimination in learning by increasing the rate at which people with disabilities participate in lifelong education, which is ten times lower than that of current non-disabled people[11].

However, people with disabilities have only limited opportunities for lifelong learning. In particular, the rate of participating in lifelong learning is even worse for people with developmental disabilities, such as intellectual disabilities and autistic disorders, with relatively severe disabilities. According to data from the National Statistical Portal in 2017, 34.4\% of the nation's total citizens participated in lifelong learning, whereas more than $98.5 \%$ of the disabled did not [12][13]. In the lifelong-education status, the participation rate of people with developmental disabilities such as intellectual disability and autism was about $4.8 \%$ (as of 2011), which is 10 times lower than that of $44.5 \%$ of all adults. Only $2.5 \%$ 
of adults over 25 years of age with developmental disabilities have ever used lifelong education[14].

Considering that most people with developmental disabilities return to their homes or facilities where they were born and raised after graduating from school without obtaining a career path, such as going to school or working, educational support is needed to develop their careers and improve practical skills necessary for social integration. This is a very urgent situation. In particular, since school-age education alone is not enough for living an adult life, because of cognitive deficits for people with developmental disabilities, continuing education in adulthood can have a very positive transfer effect.

Until now, the lifelong-education policy for the disabled in Korea has been developed around and budgeted for an education program for the physically disabled who did not receive school education during school age. Relatively, continuing-education programs for adults with developmental disabilities, including intellectual disabilities, autistic disorders, and cerebral palsy, are insufficient[14]. After all, adults with developmental disabilities are still only an 'unfamiliar learner group' in the field of lifelong education. Taken together, more than $95 \%$ of people with disabilities are extremely alienated from lifelong education. The reasons for their not participating in lifelong education are various, such as lack of information on lifelong education and on lifelong-education institutions for adults with developmental disabilities, limited access opportunities, lack of lifelong-education programs that reflect the diverse needs of adults with developmental disabilities, and financial burden.

Therefore, since adults with developmental disabilities may have unavoidable constraints and burdens on their intellectual functioning and adaptive behavioral skills, it is necessary to provide continuous education that considers environmental differences, including individual and socio-economic characteristics. In other words, school-age education for people with developmental disabilities is also important; after that, lifelong education, which allows them to learn skills so that they can have jobs for self-reliance and adapt to the community, is crucial in terms of job rehabilitation and self-reliance for such people. From the standpoint of a special-education provider, the ultimate purpose of special education is to ensure that people with developmental disabilities can maintain their own happy lives, have jobs, and live independently by means of lifelong education[15].

\section{Lifelong-Education Policy and Support for People with Developmental Disabilities in Korea}

According to Kim[16], continuous education should consider the diversity and environmental differences of the disabled in order for people with significant limitations in intellectual function and adaptive behavior to be able to function independently as members of society. However, in Korea, most of their adult lives are still in the community where they are receiving vocational education in the welfare centers or vocational rehabilitation facilities for the disabled. In other words, the general lifelongeducation institution, which is a representative integrated educational environment in the community, still does not provide enough opportunities and conditions to allow the disabled to continue their adulthood education in an integrated education environment.

Now, the disabled should be able to enjoy the opportunity of education provided to the non-disabled in the community where they live. To realize this, the general lifelong-education institutes should open the doors to educational opportunities without any restrictions or conditions for the developmentally disabled. At the national level, various types of educational programs and environments for people with developmental disabilities should be followed. In addition, various kinds of support should be provided for lifelong education so that the disabled can lead voluntary and independent lives as much as possible in the community where they belong and whose culture they enjoy. Therefore, in Korea, the policy changes of lifelong education for the disabled, including the developmentally disabled, have been significantly improved. 


\subsection{Lifelong Education Rights and Policy Basis of People with Disabilities}

If we look for legal grounds for universal lifelong education in Korea, we can first see that Article 31 of the Constitution states that "the state should promote lifelong education." This emphasizes the responsibility for supporting the whole process from the recognition of lifelong-education rights for the whole nation and self-realization by means of it.

Next, Article 3 (learning rights) of the Basic Education Act of Korea emphasizes that "all citizens have the right to learn throughout their lives and to be educated according to their abilities and aptitudes." Article 10 of the same law (social education) states that "all forms of social education for the lifelong education of the people should be encouraged." Hence we can see that the Constitution guarantees the realization and right of universal lifelong education.

But above all, the basis for the realization of lifelong education of the people is found in the Lifelong Education Act, Article 4 of which stipulates that "all citizens are guaranteed equal opportunities for lifelong education." Article 9 stipulates that "the nation and local governments should make efforts to give lifelong-learning opportunities to all citizens by establishing lifelong-education facilities, training lifelong educators, developing lifelong-education programs, and funding lifelong-education institutions, etc., as defined by this law and other laws."

With the basis for universal lifelong education, the Welfare Law for the Disabled, the Special Education Act for the Disabled, and the Lifelong Education Act (revised in 2017) have begun to specify lifelong education for the disabled.

First, the Welfare Law for the Disabled emphasizes the need for measures such as improving the contents and methods of education so that the disabled can receive sufficient education in the universal approach of welfare for the disabled. This law can be interpreted as meaning that the right to lifelong education exists for any type or degree of disability; accordingly, Article 18 includes the right to receive sufficient education according to the ideology of social integration. The government's active support for this is important and emphasizes the guarantee of the right to learn and the maintenance of convenient facilities for the disabled so that the academic performance without discrimination can be done.

Based on this, the Special Education Act for the Disabled in 2008 stated lifelong education for the disabled as the law for the first time. Article 33 of the 'Establishment and Operation of a Lifelong Education Course for the Disabled' and Article 34 of the 'Lifelong Education Program for the Disabled'. However, even though these provisions legally provided support for lifelong education of the disabled, there was criticism that they could not escape the scope of special education, such as limiting the place to conduct lifelong education to school and providing only school-type education for separate specialized facilities. At the same time, the fundamental limitation of not considering the various lifelong-education needs of the disabled has been revealed. As a result, the provisions were transferred and integrated into the Lifelong Education Act revised in 2017, and a new legal and institutional basis for lifelong education for the disabled was born.

This became an opportunity to confirm its status as a meaningful system that exists within the general lifelong-education system, not a limited field specified only in the laws and regulations that apply to the disabled in Korea. It confirmed that lifelong education for the disabled is not peripheral anymore, but is mainstream within the general lifelong education system. It is facing the transition of the times to secure mutual influence and growth in the development of general lifelong education.

The revised Lifelong Education Act emphasizes the responsibility for systematic support by the state and local governments, and mainly focuses on ensuring the participation of the subjects, establishing a support system, and laying the basis for deploying professional manpower. Therefore, the environment for supporting lifelong education for the disabled, not separation, can be implemented in the general lifelong-education system.

The change of this law began to lead to changes in the institutional level for the promotion of lifelong 
education for the disabled. In other words, the Fourth Basic Plan for Lifelong-Education Promotion (2018 2022) in Korea stated the first plan to establish a lifelong-education promotion system for the disabled to expand the practical lifelong-learning opportunities of the underprivileged. Among them, what is most noteworthy is that the National Center for Lifelong-Education Promotion for the Disabled was established within the National Institute of Special Education, and the sharing system between the state, city, and province was established. Second, in order to strengthen the provision of customized lifelong education for the disabled, the plan suggests that the existing lifelong-education system and institutions should be provided with support measures to improve accessibility to broadcasting or internet.

However, there are limitations to these achievements. First, the general lifelong-education institution planned to operate 1,130 programs for the disabled by 2022, but they are insufficient compared to the number of general lifelong-education programs. Second, the contents of the disabled are not included in the strengthening of the vocational-education capacity of the industry as emphasized in this plan. Third, there are plans to train lifelong-education specialists for the elderly, but these do not include contents about training and placement of lifelong-education specialists who will be in charge of lifelong education for the disabled. That is, disabled people are excluded from the development of human resources connecting the cyclic system of 'growth-employment-welfare' which is aimed at by the lifelong-education policy of Korea by the revision of the Lifelong Education Act and the establishment of a lifelong-education system to prepare for future society. Therefore, we expect that the demand for change of these two issues will continue.

\subsection{Basis of Lifelong-Education Policy for People with Developmental Disabilities : Lifelong Education Act}

The number of people with developmental disabilities in Korea was about 203,000 as of 2015, of whom 184,000 people had intellectual disabilities, 19,000 had autistic disabilities. Although the number of people with developmental disabilities is a fraction of registered disabled people, even simple daily life as adults often requires help from others. Also, because of low functioning such as in cognitive power and communication, it is difficult for them to claim their rights or protect themselves, so they continuously become victims, such as from abuse, violence, or exploitation of the labor force. In these situations, welfare services and infrastructure for the developmentally disabled are much less than the demand, so parents and their families who care for the developmentally disabled are not free from physical, mental, and economic burdens. As a support plan for Korean society to solve this problem, the Act on the Rights and Support for People with Developmental Disabilities has been implemented since November 2016[17].

The law consists of a total of 7 chapters and 44 articles, focusing on establishing a personalized system that considers the characteristics and needs of people with developmental disabilities and establishes a personal support plan. Among them, Article 26 prescribes lifelong-education support for people with developmental disabilities. The main contents of this law are as follows. First, the lifelong-education institution defined in Article 2 of the Lifelong Education Act is designated to properly operate the curriculum for the disabled and to support the expenses required for the operation of the curriculum.

Noteworthy is that Article 19-2 of this law established the National Center for Lifelong-Education Promotion for the Disabled to support the work or promoting lifelong education for the disabled. The main contents for supporting lifelong-education for people with developmental Disabilities are the Development of a Lifelong-Education Course for People with Developmental Disabilities, and Development and dissemination of communication tools for People with Developmental Disabilities.

For improving the legal system and seeking changes, various studies on the direction of lifelongeducation support for the ultimate developmental disability have also been published. Kim outlined three 
directions of support for lifelong education for people with developmental disabilities derived by means of case analysis: 'community-centered support', 'immediate support that meets the needs of participants', and 'mutual understanding and integrated support'[6]. First, lifelong education for people with developmental disabilities should break away from facility-centered or institution-centered support that presupposes specific facilities or spaces, and promote community-centered support policies so that the entire community can function as a learning space at the same time. Because of the disability and educational characteristics of people with developmental disabilities, support that meets the needs of participants is essential. Also, since people with developmental disabilities are citizens who must coexist in local communities throughout their lives, support based on mutual understanding and integration should be provided. Second, it is necessary to immediately support lifelong education that meets the needs of participants. In other words, we need:

1) requests for lifelong education so that adults with developmental disabilities in local communities at the city and county level can participate in individualized lifelong-education programs according to individual needs and choices by means of consultation and application whenever necessary without waiting. These should lead to

2) Diagnosis (evaluation) $\rightarrow$

3) Plan establishment (education arrangement and operation) $\rightarrow$

4) Education implementation $\rightarrow$

5) Establishing a lifelong-education support system for people with developmental disabilities by means of a continuously circulating system.

6) By establishing a lifelong-education support system based on facility, learning, and manpower resources in the community, adults with developmental disabilities can contribute to the natural participation and integration of the community.

In order to properly establish a system for supporting lifelong education for persons with developmental disabilities by such means, continuous discovery of lifelong-education facilities and learning resources for persons with developmental disabilities in the region, development of lifelongeducation courses for persons with developmental disabilities based on regional characteristics, and a supply of expert lifelong-education providers for persons with developmental disabilities will be needed. We also suggest establishing a system and operating a lifelong-education support center for people with developmental disabilities as a control tower.

On the other hand, the Ministry of Education[11] announced a plan to revitalize lifelong education for the disabled in 2021. The purpose of this project is to 'guarantee the right to high-quality lifelong learning for the disabled and to strengthen the capacity to participate in the community'. First, it establishes a lifelong-learning environment that is friendly to the disabled, expands operations of lifelong-learning cities for the disabled, strengthens support for the provision of convenience, and contains a survey of the current status of education. Second, in order to strengthen support for lifelong education tailored to the disabled, various forms of lifelong-education programs for the disabled were developed and distributed, and lifelong-education courses tailored to the developmental disabilities were developed. Third, in order to strengthen the foundation for lifelong education for the disabled, it specified that an institutional foundation to establish lifelong education for the disabled and reinforce the expertise of workers and related organizations should be undertaken.

\section{The Status and Alternatives of Lifelong Education for People with Developmental Disabilities in Korea during the COVID-19 Era}

Recently, the global pandemic caused by COVID-19 has been recognized as the most sensitive social 
problem. There is no exception in terms of welfare and education for the disabled. Rather, the humanrights issue of the disabled caused by this pandemic is being dealt with more seriously. Just because people have disabilities does not guarantee that they will be more susceptible to infection by viruses such as corona, or will be exposed to serious illness. However, the chronic diseases of individuals with disabilities and the lack of adequate coping with them will certainly cause personal medical problems, and there is a very high risk that these will soon spread to families and society as a big burden.

In fact, it can be confirmed by means of various media that there is a defect in basic care for the disabled because of the spread and re-proliferation of COVID-19. In particular, as activity-support services are not provided smoothly, the dimension is very diverse, from basic hygiene to survival threats.

It is true that a crisis has also come to lifelong education for the disabled. Since most lifelongeducation facilities for the disabled are severely restricted in providing services, there is a gap in education services, especially for people with developmental disabilities; since face-to-face education services have been the main approach, adapting to non-face-to-face education has become more difficult. As a result, the burden on the handicapped party and the family was further increased. In the absence of an adequate response system of not only individuals but also families and service providers in basic information acquisition, mobility support, and convenient facilities and communication support for the disabled, a crisis in lifelong education was brought about.

According to the "COVID-19 Era Health and Life Survey of the Developmentally Disabled and Their Families" (National Association of Parents with Disabilities, Association of College Working Therapists, 2020 ), $87 \%$ of the 1,585 respondents answered that the lifestyle of people with developmental disabilities has changed negatively. Parents also reported that they were experiencing severe stress and complaining of health problems while supporting the developmentally disabled at home 24 hours a day. Accordingly, this survey emphasizes the urgent need for 'education and care support for individuals and minorities in a safe and quarantined place', 'economic support', and 'expanding service hours for personal assistance services'[18].

Such a phenomenon implies that the foundation for self-reliance, continuous self-development, and self-realization by means of the provision of ultimate lifelong-learning opportunities and revitalization of community participation is precarious. In other words, the suspension or restriction of lifelonglearning service has led to restrictions on basic social exchanges and participation in cultural activities. Prior to that, information or educational materials for online learning for people with developmental disabilities who had intellectual or behavioral developmental problems were not sufficiently developed and accumulated. Personnel to play the role of learning leaders by reflecting the needs or desires of such learners and their expertise are still insufficient.

Therefore, realization of the right to education of the disabled in a pandemic such as COVID-19 is very important for smooth social adaptation, activation of participation, self-development, and realization. Regarding this, the latest research results that suggested the guarantee and direction of lifelong education for the disabled in the so-called "untact era" are as follows [19][20].

First, by ensuring accessibility for learners with disabilities, providing communication and manpower for online classes, distributing teaching guidelines for learners with disabilities, expanding direct homevisit personal services, such as tours of educators, for lifelong-education learners with disabilities and related institutions.

Second, in order to devise countermeasures for learners with complex needs, it is necessary to establish an emergency-care support system according to the needs of special-education subjects, to develop and disseminate appropriate contents for learners with disabilities, and to support individual education plans for learners with disabilities.

Last, it is necessary to establish councils at the community level, and to lay the foundation for solidarity and cooperation in disastrous situations such as COVID-19. 


\section{Conclusions}

In this study, literature reviews and relevant law analysis on lifelong education for people with disabilities were selected as the key research methods, considering the following: the concept, necessity, and significance of lifelong education for the disabled, the reality and limitations of lifelong education for the developmentally disabled in Korea, changes in legal and institutional policies, and the reality and alternatives of lifelong education. We also included the problems caused by COVID-19 and alternatives of lifelong education for people with developmental disabilities.

We have arrived at the following discussions of and suggestions about the tasks that must be undertaken in order to revitalize lifelong education for the developmentally disabled in Korea in the future. First, it is necessary to establish or clarify the concept of lifelong education for the disabled. This will serve as the basis for all disciplines, especially to suggest the direction to properly accept the rights and reality of lifelong education of people with developmental disabilities and will contribute to the definition of concepts in the legal and institutional dimensions. Second, it is necessary to conduct basic research to establish the theoretical and ideological foundation for lifelong education for the disabled. In other words, the research should be more active, so that the concept can be systematized by means of philosophical consideration and thinking about the lifelong-education approach for the disabled. Only then can the educational objectives in this area have a strong foundation, and the direction of policy and practice that can reach the right to learn and self-realization in the real anthropological level can be prepared. Third, in order to realize the goals of social inclusion, independent living, self-advocacy, and self-realization pursued for the welfare of the disabled, policy consideration without discrimination and an active participation plan should be continuously developed for adults with developmental disabilities. This has considerable implications for their quality of life in reliable community housing and minimally restricted environments[21].

Consequently, from the standpoint of living under the care of parents at home even as adults, continuing education should develop new competencies, establish an integrated model for independent living, and be recognized for disability characteristics by means of various programs. At the same time, efforts are required to ensure stable and universal support, and even with a legal basis, a system of continuous monitoring of the level of execution must be established. Fourth, lifelong education for the disabled should build an integrated operating model in the organic cooperation system between general lifelong education, welfare for the disabled, and special education for the disabled. By means of this, special needs for the disabled as learners should be connected in various ways by various types of disabilities, including developmental disabilities, and customized teaching and learning methods and environments should be created. As suggested by Kim[6], this is in line with the establishment of a lifelong-education support system for the fundamental developmental disabilities. Fifth, along with the expansion of the budget for activating lifelong education for adults with developmental disabilities, the system for linking lifelong education based on the National Lifelong Education Promotion Center for the Disabled must be further strengthened, as is necessary to promote and review the ultimate lifelongeducation policy for the disabled in Korea, such as reducing the burden of families with disabilities, fostering and arranging professional personnel, and creating an integrated educational environment for disabled and non-disabled people. Sixth, it is important to recognize the crisis of the COVID-19 era as an opportunity. In other words, we must strive to recognize, settle, and develop a new lifelong-education paradigm in the eras of "With Corona" and "Post Corona". The goal should be to prepare a new opportunity for ultimate integration so that the nation, society, and local communities can work together, based on the face-to-face and non-face-to-face optimal innovative lifelong-learning plan and guarantee of accessibility. Last, it is necessary to establish councils at the community level and to lay the foundation for solidarity and cooperation in disastrous situations such as Covid-19. 
However, since we conducted this research as a literature research centered on existing data such as prior researches and analysis of related laws and regulations, there were constraints to grasping the recent situation by using a our own research method. Therefore, we hope that the empirical studies on the suggestion of more reasonable data on the needs for lifelong education and social awareness of adults with developmental disabilities in Korea, practical measures according to policy changes and disaster situations such as COVID-19 will be given empathsis through subsequent studies.

\section{Acknowledgments}

This paper was supported by Joongbu University Research \& Development Fund, in 2020.

\section{References}

[1] S. H. Han, Lifelong Education: Pedagogy of the Lifelong Learning Society, Seoul: Hakjisa, (2008)

[2] E. Y. Jeong, Analysis on the Perception of Lifelong Education Concept for people with developmental disabilities using Q-Methodology, Dankook University, Doctoral Dissertation, (2017)

[3] G. Y. Kim, In-Depth Interview with Parents on Participation in Transition Education after School-Age for the Students with Developmental Disability, The Journal of the Korean Association on Developmental Disabilities, (2012), Vol.16, No.2, pp.1-21, UCI : G704-SER000009845.2012.16.2.004

[4] S. W. Kang, Lifelong Education for adults with disabilities: from exclusion to inclusion, Journal of Lifelong Education, (2013), Vol.19, No.1, pp.55-84, UCI : G704-000781.2013.19.1.003

[5] The 4th Basic Plan for Lifelong Education Promotion [2018-2022], Ministry of Education, (2018)

[6] J. Y. Kim, A Study on the Development of a Lifelong Education Support System Model for the People with Developmental Disabilities: Focused on the Case of Gyeonggi-do, The Study of Lifelong Education and Welfare for People with Disabilities, (2020), Vol.6, No.2, pp.1-28.

[7] J. R. Yun, J. K. Yang, S. O. Won, B. H. Kang, I. S. Jeong, A Study on the Lifelong Education Model of the People with Adult Development Disabilities, Gyeonggi: National Institute of Special Education, (2010)

[8] E. H. Baek, S. C. Kwak, B. U. Jeon, J. I. Kim, The Status of Lifelong Learning Program for People with Disabilities in Korea, Korean Journal of Special Education, (2001), Vol.36, No.1, pp.169-205.

[9] E. N. Rha, D. Y. Kim, Lifelong Education Center for People with Developmental Disabilities: The Current Status \& Future Direction, The Study of Lifelong Education and Welfare for People with Disabilities, (2017), Vol.3, No.1, pp.3164.

[10] D. S. Kang, Development and Application Effects of an Independent Living-focused Lifelong Education Program Targeting Adults with Developmental Disabilities, Changwon University, Doctoral dissertation, (2016)

[11] Plans to revitalize lifelong education for the disabled ('20 '22), Ministry of Education, (2018 2020)

[12] Lifelong Learning Individual Survey: Lifelong Learning Participation Rate, Korean Statistical Information Service (2017)

[13] Actual status survey of the disabled in Korea, Korea Institute for Health and Social Affairs, (2017)

[14] A Study on the Promotion of Lifelong Education for People with Development Disabilities, Seoul Parents Society For The Disabled Association, (2014)

[15] J. S. Kim, Continuing education of adults with developmental disabilities, Jeonbuk University, Master's thesis, (2015)

[16] S. K. Kim, An Activating Plan for Lifelong Education of People with Developmental Disabilities, Korea National Open University, Master's thesis ,(2012) 
[17] K. J. Lee, Y. Y. Choi, The Latest of Social Welfare for People with Disabilities, 2nd edition, Seoul: Hakjisa, (2020)

[18] Y. S. Jeong, Education plan and support in the field of lifelong education for the disabled in the Untact era, 2020 Joint Academic Conference Paper Collection, (2020)

[19] S. H. Lee, B. H. Lee, Current Status of Support for the Disabled and Policy Tasks Following the COVID-19 Outbreak, Heath \& Welfare, (2020), Vol.22, No.3, pp.7-34, DOI : 10.23948/kshw.2020.09.22.3.7

[20] G. B. Jeon, COVID-19 and the Lives of Disabled Persons: The Current Status and Countermeasures, Journal of Critical Social Welfare, (2020), No.68, pp.173-207, DOI : 10.47042/ACSW.2020.08.68.173

[21] E. H. Jung, Y. H. Yeo, Residential Factors Affectiong Quality of Life of People with Disabilities, Asia-pacific Journal of Psychology and Counseling, (2020), Vol.4, No.1, pp.15-20. 